REFERENCE:

[1] Nash P, et al. Arthritis Rheumatol 2017;69(suppl 10):619.

Acknowledgements: Study sponsored by Pfizer Inc. Medical writing support was provided by K Nicholson of CMC and funded by Pfizer Inc.

Disclosure of Interest: F. Behrens Grant/research support from: AbbVie, Chugai, Novartis, Pfizer Inc, Prophylix, Roche, Consultant for: AbbVie, Biotest, BMS, Celgene, Chugai, Eli Lilly, Genzyme, Janssen, MSD, Novartis, Pfizer Inc, Roche, UCB, Speakers bureau: AbbVie, Biotest, BMS, Celgene, Chugai, Eli Lilly, Genzyme, Janssen, MSD, Novartis, Pfizer Inc, Roche, UCB, J. Gomez-Reino Grant/ research support from: AbbVie, MSD, Pfizer Inc and Roche, Consultant for: Pfizer Inc, Speakers bureau: AbbVie, Biogen, Bristol-Myers Squibb, Janssen, MSD, Pfizer Inc and Roche, P. Nash Grant/research support from: AbbVie, BMS, Eli Lilly, Janssen, Novartis, Pfizer Inc, Roche, Sanofi, UCB, Consultant for: AbbVie, BMS, Eli Lilly, Janssen, Novartis, Pfizer Inc, Roche, Sanofi, UCB, Speakers bureau: AbbVie, BMS, Eli Lilly, Janssen, Novartis, Pfizer Inc, Roche, Sanofi, UCB, D. Gladman Grant/research support from: AbbVie, Amgen, Bristol-Myers Squibb, Celgene, Eli Lilly, Janssen, Novartis, Pfizer Inc, UCB, Consultant for: AbbVie, Amgen, Bristol-Myers Squibb, Celgene, Eli Lilly, Janssen, Novartis, Pfizer Inc, UCB, O. FitzGerald Grant/research support from: AbbVie, BMS, Novartis, Pfizer Inc, Consultant for: Amgen, Celgene, Eli Lilly, Janssen, C. Ritchlin Grant/research support from: AbbVie, Amgen and UCB, Consultant for: AbbVie, Amgen, Celgene, Janssen, Novartis, Pfizer Inc, Sun and UCB, E. Kudlacz Shareholder of: Pfizer Inc, Employee of: Pfizer Inc, J. Wu Shareholder of: Pfizer Inc, Employee of: Pfizer Inc, C. Wang Shareholder of: Pfizer Inc, Employee of: Pfizer Inc, A. Romero Shareholder of: Pfizer Inc, Employee of: Pfizer Inc DOI: 10.1136/annrheumdis-2018-eular.3210

\section{AB0922 METABOLIC SYNDROME IS ASSOCIATED WITH ACTIVE DISEASE IN PSORIATIC ARTHRITIS AND MAY CONTRIBUTE TO DEVELOPMENT OF SYNDESMOPHYTES}

P. Sanci', G. Kenar ${ }^{2}$, B. Zengin ${ }^{2}$, S. Uslu' ${ }^{2}$, A. Koken ${ }^{2}$, H. Yarkan², H. Ellidokuz ${ }^{3}$, G. Can ${ }^{2}$, M. Birlik ${ }^{2}$, F. Onen ${ }^{2} .{ }^{1}$ Internal Medicine; ${ }^{2}$ Rheumatology; ${ }^{3}$ Preventive Oncology, Dokuz Eylul University School of Medicine, Izmir, Turkey

Background: An increased prevalence of metabolic syndrome (MetS) has been reported in psoriatic arthritis (PsA) suggesting an association between the inflammation and MetS.

Objectives: The aim of this study is to investigate its relationship with disease activity in patients with PsA. We also evaluated whether an association exists between MetS and axial involvement in PsA.

Methods: This study included patients with PsA followed in the Rheumatology outpatient clinic at Dokuz Eylul University. Age-matched patients with Takayasu arteritis (TA), an inflammatory systemic disease, were enrolled as diseased controls. The NCEP-ACT III criteria were used to identify subjects with MetS. Disease activity was assessed in patients with PsA by using several parameters including BASDAI, ASDAS, VAS patients' and physician' global, Tender and Swollen joint assessment (28/68), DAS28, DAPSA, CPDAI and SPARCC Enthesitis Index. ESR and serum CRP levels were measured. BASFI and BASMI were used to evaluate functional status and $\mathrm{HAQ}, \mathrm{ASQ} \mathrm{L}$ and DLQI to evaluate health and PASI to measure the severity of psoriasis. Hand and pelvis X-rays and sacroiliac joint MRIs were performed when indicated.

Results: There were 104 PsA patients $(63.5 \% \mathrm{~F}$; mean age: $50.9 \pm 13.0$ years) who fulfilled the CASPAR criteria and 28 TA patients $(89 \% \mathrm{~F}$, mean age: 46.3 \pm 9.1 ) who fulfilled the ACR 1990 criteria. The prevalence of MetS was found to be considerably higher in PsA patients compared to TA patients $(45.2 \%$ and $21.4 \%$ respectively, $p<0.001$ ). In the comparison of PsA patients with and without MetS, no differences were found regarding treatment frequencies of NSAIDs, glucocorticoids, DMARDs and anti-TNFs and also mean glucocorticoid dosages. PsA patients with MetS had higher BASDAI, BASFI, BASMI, VAS, ASqOL, CPDAI, ASDAS and HAQ scores compared to PsA patients without MetS (table 1). More patients with syndesmophytes were found among PsA patients with MetS compared to those without MetS $(p=0.027)$. There were no differences in indexes related predominantly peripheral involvement, such as tender and swollen joint counts, enthesitis score and presence of dactylitis. In multivariable regression analysis, presence of syndesmophytes had no relationship with MetS, but still related with ESR and BASMI.
Abstract AB0922 - Table 1. Clinical features and disease activity parameters in PsA patients with and without MetS.
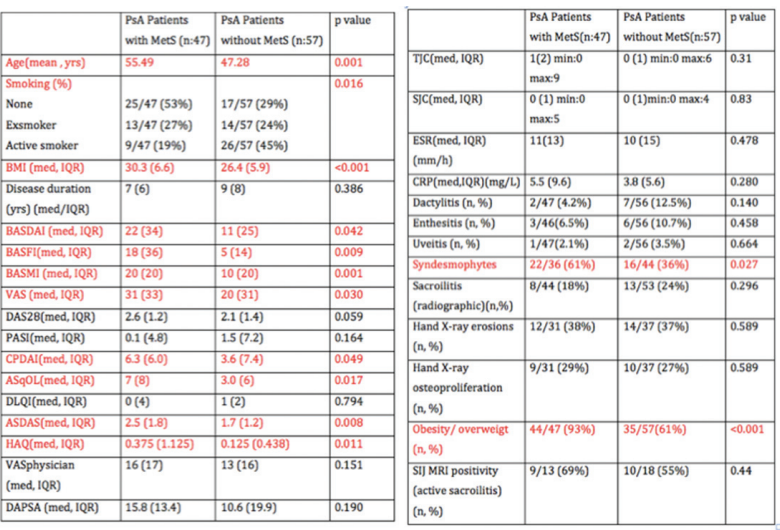

Conclusions: This study demonstrates a higher prevalence of MetS in PsA patients compared to TA. It also suggests that MetS might be associated with high disease activity and more severe disease especially in patients with axial involvement.

Disclosure of Interest: None declared

DOI: 10.1136/annrheumdis-2018-eular.5663

\section{AB0923 AUTONOMIC DYSFUNCTION IN PSORIATIC ARTHRITIS PATIENTS AND PSYCHO-EMOTIONAL DISORDERS FREQUENCY}

I. Blaginina ${ }^{1}$, O. Rebrova ${ }^{1}$, A. Blagodarenko ${ }^{1}$, N. Bludova ${ }^{1}$, I. Pokryshka ${ }^{2} .{ }^{1}$ internal medcine, SI "Lugansk State Medical University"; ${ }^{2}$ rhematology, Lugansk repuplic clinical hospital, Lugansk, Ukraine

Background: Progressive autonomic dysfunction syndrome development is a characteristic for the most of immune inflammatory processes. Pain syndrome chronization in patients with psoriatic arthritis (PsA) is one of the leading factors contributing to the development of psycho-emotional disorders. They, in turn exacerbate the disorders of the autonomic nervous system.

Objectives: to evaluate function of the autonomic in PsA patients and the presence of psycho-emotional disorders in them

Methods: 73 patients with PsA ( $>5 \mathrm{SJC}$ and $>5$ TJC; CRP $>0,3 \mathrm{mg} / \mathrm{dL}$ ) were examined by psycho-emotional testing using the Spielberger anxiety and Hamilton depression scales. Autonomic disorders were detected by "Vein-Patient"-VP method's questionnaire, filled by the patient (when more than 15 points - autonomic dysfunction is possible (AD)) and "Vein-Doctor"-VD questionnaire, filled by the doctor (more than 25 points - confirmation of the presence of $A D$ ); studied the general indicators of heart rate variability (HRV) - mode (Mo), mode amplitude (AMo), autonomic equilibrium index (AEI), activity index of regulatory systems (AIRS); spectral characteristics - standard deviation of normal RR intervals (SDNN); square root of the mean of the sum of the squares of the differences between consecutive RR-intervals (RMSSD) and the ratio of balance between sympathetic and parasympathetic activities (LF/HF) of autonomic nervous system (ANS). All the patients received MTX in a stable dose for 6 months at least, prior the time of the study.

Results: in 39 PsA patients $(53,4 \%)$ increased reactive anxiety $(37,0 \pm 1,5$ points and personal anxiety $(45,4 \pm 1,5$ points) levels were determined as results of testing. They made up the 1 st observation group, and the remaining 34 patients - the 2nd observation group. In the first group, according to the questionnaire VP and VD more significant excess of the norm was defined $(19.79 \pm 0.54$ points and 29.8 \pm 0.77 points respectively) than in the 2 nd group $(16,92 \pm 0,62$ and $27,1 \pm 0,8$ points). The decrease of the SDNN и RMSSD in comparison with norm was revealed in the both groups, that evidences an inhanced sympathetic regulation. However, more significant LF/HF growth $(4,15 \pm 0,64)$ and SDNN decrease $(22,4$ $\pm 5,6 \mathrm{~ms})$ in the $1 \mathrm{st}$ group, than in the 2-nd $(3,0 \pm 0,86 ; 29,1 \pm 8,4 \mathrm{~ms}$, respectively) occurred. It indicates a link between the increase in the sympathetic level of regulation and the presence of signs of psycho-emotional disorders. And also the growth of AMO in the 1 st group $(47,9 \pm 8,4 \%)$ shows the strength of sympathetic mobilising influence and evidences an increased medullary vasomotor centre activation and growth of sympathetic regulation in PsA patients with depression. In general, the severity of changes in HRV in PsA patients can be due to a high content of pro-inflammatory cytokines, which induce the synthesis of free acid radicals and worsen ANS maintenance of the organisms`activity.

Conclusions: Emotional disorders of the anxiety-depressive spectrum contribute to the regulatory mechanisms tension increase and adaptive capabilities 